\title{
Efficacy of Ortus 05 SC (fenpyroximate) in control of the strawberry mite (Phytonemus pallidus Banks.) on strawberry plantations after fruit harvest
}

\author{
Ocena biologicznej skuteczności preparatu Ortus 05 SC (fenpiroksymat) \\ w zwalczaniu roztocza truskawkowca (Phytonemus pallidus Banks.) \\ na truskawce po zbiorze owoców
}

\author{
Barbara H. Łabanowska
}

\begin{abstract}
Summary
The strawberry mite (Phytonemus pallidus) is a very important pest of strawberry in Poland. The pest feeds on the smallest, young folded leaves, flower buds and flowers. Plants heavily infested with mites become severely stunted and crinkled, resulting in changes in fruit size and quality. The pest easily spreads on plantation with strawberry seedlings. $P$. pallidus has to be control on many strawberry plantations however, its controls is very difficult due to the lack of registered products. Recently there was only one acaricide permitted on strawberry. The aim of these trials was to evaluate the effectiveness of fenpyroximate (Ortus 05 SC) against the strawberry mite. Ortus $05 \mathrm{SC}$ at the rate of 1.25 and $1.5 \mathrm{l} /$ ha as well as Ortus $05 \mathrm{SC}(1.125 \mathrm{l} / \mathrm{ha})+$ Slippa $(0.2 \mathrm{l} / \mathrm{ha})$ was applied twice with one week interval after strawberry harvest and it gave average level of the control (about $80 \%$ ). Ortus 05 SC used at the rate $1.0 \mathrm{l} /$ ha gave lower efficacy (30\%), especially on heavily infested plantation. In 2013 Ortus 05 SC was registered for control of the strawberry mite in Poland and may be use once during a vegetation season.
\end{abstract}

Key words: strawberry mite; Phytonemus pallidus; control; fenpyroximate; Ortus 05 SC; strawberry

\begin{abstract}
Streszczenie
Roztocz truskawkowiec (Phytonemus pallidus) jest bardzo groźnym szkodnikiem truskawki. Jego larwy i osobniki dorosłe żerują na najmłodszych liściach, pąkach kwiatowych i kwiatach, co jest przyczyną karłowacenia roślin oraz znacznej redukcji wielkości owoców i owocowania roślin. Roztocz ten bardzo łatwo rozprzestrzenia się z sadzonkami, a także na plantacji przemieszczając się pomiędzy roślinami. Musi on być zwalczany na wielu plantacjach, chociaż jest bardzo trudnym do zniszczenia, gdyż od kilku lat brakuje skutecznych środków. Ostatnio zarejestrowany był tylko jeden akarycyd, do stosowania tylko po zbiorze owoców. Celem prowadzonych doświadczeń była ocena przydatności fenpiroksymatu, substancji czynnej preparatu Ortus 05 SC do zwalczania roztocza truskawkowca. Ortus 05 SC w dawce 1,25 i 1,5 I/ha oraz Ortus 05 SC z dodatkiem zwilżacza Slippa (0,2 I/ha) zastosowany dwukrotnie po zbiorze owoców truskawki, zwalczał roztocza na poziomie średnio około $80 \%$. Ortus 05 SC zastosowany w dawce $1,0 \mathrm{l} / \mathrm{ha}$ był mniej skuteczny (około $30 \%$ po 3 tygodniach), szczególnie na plantacji bardzo silnie zasiedlonej przez roztocza. W 2013 roku został zarejestrowany do zwalczania roztocza truskawkowca na truskawce i może być zastosowany jeden raz w sezonie.
\end{abstract}

Słowa kluczowe: roztocz truskawkowiec; Phytonemus pallidus; zwalczanie; fenpiroksymat; Ortus 05 SC; truskawka

Instytut Ogrodnictwa

Konstytucji 3 Maja 1/3, 96-100 Skierniewice

Barbara.Labanowska@inhort.pl 


\section{Wstęp / Introduction}

Roztocz truskawkowiec (Phytonemus pallidus) jest bardzo groźnym szkodnikiem truskawki w Polsce (Łabanowska 2000, 2006a), który występuje w różnym nasileniu, praktycznie na wszystkich uprawianych odmianach truskawki (Łabanowska 2004, 2006b) i dość szybko rozprzestrzenia się pomiędzy roślinami i odmianami na plantacji (Łabanowska 2004). Jest on poważnym zagrożeniem także w innych krajach europejskich (Alford 1972, 2007; Stenseth i Nordby 1976; Raudonis 2002), dlatego też prowadzone są liczne prace nad możliwością jego zwalczania (Łabanowska 1992, 1995, 2006a, c, d; Tuovinen 2000; Easterbrook i wsp. 2001; Raudonis 2005, 2006b).

Roztocz truskawkowiec jest szkodnikiem bardzo trudnym do zniszczenia. Przez wiele lat do jego zwalczania stosowano takie substancje czynne, jak np. endosulfan, amitraz, propragit, które zostały wycofane z ochrony truskawki, ze względu na wysoką toksyczność. Od lat wprowadza się Integrowaną Produkcję/Integrowaną Ochronę także w uprawie truskawki, dlatego też bardzo ważne jest stosowanie środków bardziej selektywnych, bezpiecznych dla fauny pożytecznej, w tym roztoczy drapieżnych, redukujących roztocza truskawkowca (Edland 1994; Cross i wsp. 1996; Tuovinen 2000; Easterbrook i wsp. 2001; Raudonis 2006a; Svensson 2008). W ostatnim czasie w Polsce do zwalczania roztocza dozwolony był tylko Sanmite 20 WP (pirydaben) w dawce 2,25 kg/ha - dwukrotnie wyższej niż do zwalczania przędziorka chmielowca, ale zabiegi mogły być prowadzone jedynie po zbiorze owoców. Konieczne było poszukiwanie innych, bardziej bezpiecznych metod zwalczania szkodnika.

Celem przedstawionych badań była ocena przydatności fenpiroksymatu, substancji czynnej preparatu Ortus 05 SC do zwalczania roztocza truskawkowca po zakończonym zbiorze owoców.

\section{Materiały i metody / Materials and methods}

Doświadczenia prowadzono na prywatnych plantacjach truskawki w województwie łódzkim w latach 2009-2010. Zakładano je na 2-3-letnich uprawach odmiany Darselekt i Honeoye, metodą bloków losowanych w 4 powtórzeniach. Jedno poletko-powtórzenie obejmowało powierzchnię $22 \mathrm{~m}^{2}$ (4 rzędy $\times 5,5 \mathrm{~m}$ długości). Zabiegi zwalczające przeprowadzano po zakończonym zbiorze owoców, opryskiwaczem plecakowo-motorowym „Stihl” SR 420 zużywając 7501 cieczy użytkowej na ha. W każdym doświadczeniu wykonywano 2 zabiegi zwalczające, w odstępie 7-10 dni. Oceniano przydatność preparatu Ortus 05 SC, a jako preparat referencyjny zastosowano Sanmite 20 WP. Terminy zabiegów podano w tytułach tabel.

Liczebność populacji roztocza truskawkowca określano bezpośrednio przed opryskiwaniem, tydzień po pierwszym oraz 1, 2, 3 i 4 tygodnie po drugim zabiegu. W tym celu z każdego poletka pobierano losowo po 10 najmłodszych, zwiniętych jeszcze liści. W laboratorium każdy liść prze- glądano pod mikroskopem stereoskopowym i określano liczbę stadiów ruchomych (osobniki dorosłe i larwy) oraz jaj roztocza.

Wyniki opracowano statystycznie metoda analizy wariancji na wartościach przekształconych według transformacji logarytmicznej $\mathrm{y}=\log (\mathrm{x}+1)$, gdzie: $\mathrm{x}-$ liczba osobników (stadiów ruchomych lub jaj) na 10 liści. Istotność różnic między średnimi oceniono za pomocą testu Newmana-Keulsa przy poziomie istotności $p=0,05 \%$. $\mathrm{Na}$ podstawie wartości rzeczywistych obliczono śmiertelność według wzoru Abbotta (1925), który ma postać C\% $=$ A-B/A × 100, gdzie: A - liczba osobników na poletku kontrolnym, B - liczba osobników na poletku traktowanym preparatem Ortus 05 SC lub Sanmite 20 WP.

\section{Wyniki i dyskusja / Results and discussion}

Preparat Ortus 05 SC (fenpiroksymat) zastosowany dwukrotnie na plantacji w Czatolinie, po zbiorze owoców i skoszeniu liści truskawki, istotnie zredukował populację roztocza truskawkowca (tab. 1). Preparat ten w niższej dawce $(1,0$ 1/ha) przez pierwsze dwa tygodnie po dwóch zabiegach zwalczał skutecznie roztocza truskawkowca (efektywność 88,5-85,3\%), a później tylko ograniczał jego występowanie (tab. 2). Użyty w wyższej dawce (1,25 1/ha) wykazał średnią (76-75\%), a po 3 tygodniach wysoką efektywność zwalczania szkodnika $(88,9 \%)$. Po zastosowaniu preparatu Ortus $05 \mathrm{SC}$ z dodatkiem zwilżacza Slippa nie uzyskano zwiększonej efektywności. Efektywność preparatu Ortus 05 SC była podobna, jak stosowanego akarycydu standardowego - Sanmite 20 WP $(2,25 \mathrm{~kg} / \mathrm{ha})$.

W doświadczeniu prowadzonym w Potoku Białym, na plantacji bardzo silnie zasiedlonej przez roztocza truskawkowca, preparat Ortus $05 \mathrm{SC}$ istotnie redukował jego liczebność przez okres 3 tygodni (tab. 3). Zastosowany w dawce 1,25 1/ha oraz 1,0 1/ha + Slippa 0,2 1/ha zapewnił dobrą lub średnią skuteczność zwalczania stadiów ruchomych do 2 tygodni po drugim zabiegu (tab. 4), zaś w dawce 1,0 1/ha tylko ograniczał liczebność szkodnika. Efektywność preparatu Ortus 05 SC była podobna, jak preparatu porównawczego Sanmite $20 \mathrm{WP}$.

$\mathrm{Na}$ plantacji w Bobrowej, preparat Ortus $05 \mathrm{SC}$ w dawce 1,125 i 1,5 1/ha oraz 1,125 1/ha + Slippa 0,2 1/ha istotnie redukował liczebność roztocza truskawkowca (tab. 5). Wyniki nie różniły się istotnie od tych po zastosowaniu preparatu porównawczego - Sanmite $20 \mathrm{WP}$. Ortus 05 SC wykazał dobrą lub średnią skuteczność zwalczania stadiów ruchomych i jaj szkodnika $(81,4-$ 95,2\%) w 3-4 tygodnie po drugim zabiegu (tab. 6). Preparat użyty jako referencyjny - Sanmite 20 WP zapewnił wysoką skuteczność w zwalczaniu stadiów ruchomych i jaj szkodnika (odpowiednio 97,8 i 98,7\%).

W doświadczeniu wykonanym na plantacji w miejscowości Jamno uzyskano zwalczanie roztocza truskawkowca na poziomie średnim lub dobrym, zależnie od dawki preparatu i terminu obserwacji (tab. 7, 8). Efektywność ta była podobna do uzyskanej z preparatem referencyjnym Sanmite 20 WP. 
Przedstawione wyniki kilku doświadczeń wskazują, że preparat Ortus 05 SC zastosowany dwa razy w odstępie około 7 dni, po zakończonym zbiorze owoców truskawki, istotnie redukował liczebność populacji roztocza truskawkowca. We wszystkich doświadczeniach liczebność jaj była proporcjonalna do liczebności stadiów ruchomych szkodnika. Wyniki te są potwierdzeniem pierwszych doświadczeń (Łabanowska 2003), w których preparat Ortus 05 SC zastosowany dwukrotnie po zbiorze owoców dość skutecznie ograniczał liczebność roztocza truskawkowca. Podobnie według Łabanowskiej (2007) Ortus $05 \mathrm{SC}$ zarejestrowany wówczas i stosowany dwukrotnie do zwalczania przędziorka chmielowca, redukował liczebność populacji roztocza truskawkowca. Fenpiroksymat jako Ortus 05 SC redukował także wielkopąkowca porzeczkowego - Cecidophyopsis ribis (Łabanowska 2011). $\mathrm{W}$ innych krajach europejskich do zwalczania roztocza truskawkowca dozwolone są również inne substancje czynne, takie jak np. abamektyna, metiokarb oraz zaleca się biologiczne zwalczanie przy pomocy roztoczy drapieżnych z rodziny Phytoseiidae (Tuovinen 2000; Easterbrook i wsp. 2001; Svensson 2008). W Polsce dobre wyniki w zwalczaniu roztocza uzyskano po zastosowaniu abamektyny - preparat Vertimec 018 EC (Łabanowska 1992), bifenazate jako Floramite 240 SC, spirodiklofenu -

Tabela 1. Efektywność preparatu Ortus 05 SC (fenpiroksymat) w zwalczaniu roztocza truskawkowca (P. pallidus) na truskawce wyrażona liczbą stadiów ruchomych oraz jaj na 1 liść. Czatolin, terminy zabiegów: 28.07 i 6.08.2009

Table 1. Efficacy of Ortus 05 SC (fenpiroxymate) in the control of the strawberry mite (P.pallidus) on strawberry expressed as number of motile forms and eggs. Czatolin, date of treatments: July 28 and August 6, 2009

\begin{tabular}{|c|c|c|c|c|c|c|c|}
\hline \multirow{2}{*}{$\begin{array}{c}\text { Kombinacja } \\
\text { Treatment }\end{array}$} & \multirow{2}{*}{$\begin{array}{c}\text { Dawka } \\
\text { Rate } \\
{[1 / \mathrm{kg} / \mathrm{ha}]}\end{array}$} & \multirow{2}{*}{$\begin{array}{l}\text { Przed } \\
\text { zabiegiem } \\
\text { Before } \\
\text { treatment }\end{array}$} & \multicolumn{5}{|c|}{$\begin{array}{l}\text { Liczba osobników na } 1 \text { liść } \\
\text { No. of motile forms and eggs per } 1 \text { leaf }\end{array}$} \\
\hline & & & 6.08 & 17.08 & 24.08 & 31.08 & 10.09 \\
\hline \multicolumn{8}{|c|}{ Stadia ruchome - Motile forms } \\
\hline Kontrolna - Untreated & - & $13,6 \mathrm{a}$ & $14,3 \mathrm{~b}$ & $31,4 \mathrm{~b}$ & $26,6 \mathrm{~b}$ & $37,2 \mathrm{~b}$ & $35,7 \mathrm{~b}$ \\
\hline Ortus $05 \mathrm{SC}$ & 1,0 & $13,0 \mathrm{a}$ & $2,1 \mathrm{a}$ & $3,6 \mathrm{a}$ & $5,8 \mathrm{a}$ & $8,1 \mathrm{a}$ & $9,5 \mathrm{a}$ \\
\hline Ortus $05 \mathrm{SC}$ & 1,25 & $11,0 \mathrm{a}$ & $1,4 \mathrm{a}$ & $4,5 \mathrm{a}$ & $4,5 \mathrm{a}$ & $3,5 \mathrm{a}$ & $10,2 \mathrm{a}$ \\
\hline Ortus 05 SC + Slippa & $1,0+0,2$ & $18,1 \mathrm{a}$ & $1,7 \mathrm{a}$ & $2,3 \mathrm{a}$ & $6,4 \mathrm{a}$ & $5,5 \mathrm{a}$ & $15,8 \mathrm{a}$ \\
\hline Sanmite $20 \mathrm{WP}$ & 2,25 & $12,7 \mathrm{a}$ & $1,6 \mathrm{a}$ & $1,2 \mathrm{a}$ & $0,7 \mathrm{a}$ & $3,7 \mathrm{a}$ & $1,3 \mathrm{a}$ \\
\hline \multicolumn{8}{|c|}{ Jaja - Eggs } \\
\hline Kontrolna - Untreated & - & $26,8 \mathrm{a}$ & $24,1 \mathrm{~b}$ & $25,2 \mathrm{~b}$ & $42,5 \mathrm{~b}$ & $45,4 \mathrm{~b}$ & $52,3 \mathrm{~b}$ \\
\hline Ortus $05 \mathrm{SC}$ & 1,0 & $27,9 \mathrm{a}$ & $1,9 \mathrm{a}$ & $3,2 \mathrm{a}$ & $7,7 \mathrm{a}$ & $11,0 \mathrm{a}$ & $11,4 \mathrm{a}$ \\
\hline Ortus $05 \mathrm{SC}$ & 1,25 & $21,6 \mathrm{a}$ & $1,6 \mathrm{a}$ & $4,1 \mathrm{a}$ & $8,5 \mathrm{a}$ & $5,6 \mathrm{a}$ & $9,8 \mathrm{a}$ \\
\hline Ortus 05 SC + Slippa & $1,0+0,2$ & $29,1 \mathrm{a}$ & $1,1 \mathrm{a}$ & $1,6 \mathrm{a}$ & $9,5 \mathrm{a}$ & $5,8 \mathrm{a}$ & $14,4 \mathrm{a}$ \\
\hline Sanmite $20 \mathrm{WP}$ & 2,25 & $27,8 \mathrm{a}$ & $2,4 \mathrm{a}$ & $1,3 \mathrm{a}$ & $1,1 \mathrm{a}$ & $3,9 \mathrm{a}$ & $1,8 \mathrm{a}$ \\
\hline
\end{tabular}

Wartości średnie oznaczone w kolumnach tą samą literą nie różnią się istotnie przy p $=0,05$, test Newmana-Keulsa

Means followed by the same letter in each column are not significantly different (Newman-Keuls' test, $\mathrm{p}=0.05$ )

Tabela 2. Efektywność zwalczania roztocza truskawkowca (P. pallidus) na truskawce obliczona według wzoru Abbotta [\%]. Czatolin 2009

Table 2. Efficacy of strawberry mite (P. pallidus) control on strawberry plants according to Abbott's formula [\%]. Czatolin 2009

\begin{tabular}{|c|c|c|c|c|c|c|}
\hline \multirow{2}{*}{$\begin{array}{c}\text { Kombinacja } \\
\text { Treatment }\end{array}$} & \multirow{2}{*}{$\begin{array}{c}\text { Dawka } \\
\text { Rate } \\
{[1 / / \mathrm{kg} / \mathrm{ha}]}\end{array}$} & \multicolumn{5}{|c|}{$\begin{array}{c}\text { Efektywność - Efficacy } \\
{[\%]}\end{array}$} \\
\hline & & 6.08 & 17.08 & 24.08 & 31.08 & 10.09 \\
\hline \multicolumn{7}{|c|}{ Stadia ruchome - Motile forms } \\
\hline Ortus $05 \mathrm{SC}$ & 1,0 & 85,3 & 88,5 & 78,2 & 78,2 & 73,4 \\
\hline Ortus $05 \mathrm{SC}$ & 1,25 & 90,2 & 85,7 & 83,1 & 90,6 & 71,4 \\
\hline Ortus 05 SC + Slippa & $1,0+0,2$ & 88,1 & 92,7 & 75,9 & 85,2 & 55,7 \\
\hline Sanmite $20 \mathrm{WP}$ & 2,25 & 88,8 & 96,2 & 97,4 & 82,0 & 96,3 \\
\hline \multicolumn{7}{|c|}{ Jaja - Eggs } \\
\hline Ortus $05 \mathrm{SC}$ & 1,0 & 92,1 & 87,3 & 81,9 & 75,8 & 78,2 \\
\hline Ortus $05 \mathrm{SC}$ & 1,25 & 93,4 & 83,7 & 80,0 & 87,7 & 81,3 \\
\hline Ortus 05 SC + Slippa & $1,0+0,2$ & 95,4 & 93,6 & 77,6 & 87,2 & 72,5 \\
\hline Sanmite $20 \mathrm{WP}$ & 2,25 & 90,0 & 94,8 & 97,4 & 91,4 & 96,5 \\
\hline
\end{tabular}


Tabela 3. Efektywność preparatu Ortus $05 \mathrm{SC}$ w zwalczaniu roztocza truskawkowca ( $P$. pallidus) na truskawce wyrażona liczbą stadiów ruchomych oraz jaj na 1 liść. Potok Biały, terminy zabiegów: 6 i 14.08.2009

Table 3. Efficacy of fenpiroxymate (Ortus $05 \mathrm{SC}$ ) in the control of the strawberry mite (P. pallidus) on strawberry expressed as number of motile forms and eggs. Potok Biały, date of treatments: August 6 and 14, 2009

\begin{tabular}{|c|c|c|c|c|c|c|}
\hline \multirow{2}{*}{$\begin{array}{c}\text { Kombinacja } \\
\text { Treatment }\end{array}$} & \multirow{2}{*}{$\begin{array}{c}\text { Dawka } \\
\text { Rate } \\
{[1 / \mathrm{kg} / \mathrm{ha}]}\end{array}$} & \multirow{2}{*}{$\begin{array}{l}\text { Przed } \\
\text { zabiegiem } \\
\text { Before } \\
\text { treatment }\end{array}$} & \multicolumn{4}{|c|}{$\begin{array}{l}\text { Liczba osobników na } 1 \text { liść } \\
\text { No. of motile forms and eggs per } 1 \text { leaf }\end{array}$} \\
\hline & & & 12.08 & 20.08 & 3.09 & 29.09 \\
\hline \multicolumn{7}{|c|}{ Stadia ruchome - Motile forms } \\
\hline Kontrola - Untreated & - & $46,6 \mathrm{a}$ & $19,5 \mathrm{~b}$ & $19,3 \mathrm{~b}$ & $16,1 \mathrm{~b}$ & $8,4 \mathrm{~b}$ \\
\hline Ortus $05 \mathrm{SC}$ & 1,0 & 57,6 a & $8,2 \mathrm{ab}$ & $5,8 \mathrm{a}$ & $6,5 \mathrm{~b}$ & $10,5 \mathrm{~b}$ \\
\hline Ortus $05 \mathrm{SC}$ & 1,25 & $40,2 \mathrm{a}$ & $3,9 \mathrm{a}$ & $3,9 \mathrm{a}$ & $4,6 \mathrm{~b}$ & $8,1 \mathrm{~b}$ \\
\hline Ortus 05 SC + Slippa & $1,0+0,2$ & $28,1 \mathrm{a}$ & $4,0 \mathrm{a}$ & $4,3 \mathrm{a}$ & $5,6 \mathrm{~b}$ & $2,4 \mathrm{ab}$ \\
\hline Sanmite $20 \mathrm{WP}$ & 2,25 & $42,4 \mathrm{a}$ & $3,7 \mathrm{a}$ & $2,0 \mathrm{a}$ & $0,3 \mathrm{a}$ & $0,9 \mathrm{a}$ \\
\hline \multicolumn{7}{|c|}{ Jaja - Eggs } \\
\hline Kontrola - Untreated & - & $93,8 \mathrm{a}$ & $33,6 \mathrm{~b}$ & $35,9 \mathrm{~b}$ & $19,9 \mathrm{~b}$ & $5,6 \mathrm{a}$ \\
\hline Ortus $05 \mathrm{SC}$ & 1,0 & $102,2 \mathrm{a}$ & $16,6 \mathrm{ab}$ & $9,9 \mathrm{a}$ & $11,7 \mathrm{~b}$ & $6,1 \mathrm{a}$ \\
\hline Ortus $05 \mathrm{SC}$ & 1,25 & $74,0 \mathrm{a}$ & $8,5 \mathrm{a}$ & $9,9 \mathrm{a}$ & $5,6 \mathrm{~b}$ & $3,9 \mathrm{a}$ \\
\hline Ortus $05 \mathrm{SC}+$ Slippa & $1,0+0,2$ & $53,8 \mathrm{a}$ & $7,9 \mathrm{a}$ & $5,7 \mathrm{a}$ & $7,9 \mathrm{~b}$ & $1,6 \mathrm{a}$ \\
\hline Sanmite $20 \mathrm{WP}$ & 2,25 & $94,4 \mathrm{a}$ & $5,8 \mathrm{a}$ & $4,1 \mathrm{a}$ & $0,6 \mathrm{a}$ & $0,8 \mathrm{a}$ \\
\hline
\end{tabular}

Wartości średnie oznaczone w kolumnach tą samą literą nie różnią się istotnie przy p =0,05, test Newmana-Keulsa

Means followed by the same letter in each column are not significantly different (Newman-Keuls' test, $\mathrm{p}=0.05$ )

Tabela 4. Efektywność zwalczania roztocza truskawkowca (P. pallidus) na truskawce obliczona według wzoru Abbotta [\%]. Potok Biały 2009

Table 4. Efficacy of strawberry mite (P. pallidus) control on strawberry plants according to Abbott's formula [\%]. Potok Biały 2009

\begin{tabular}{|c|c|c|c|c|c|}
\hline \multirow{2}{*}{$\begin{array}{l}\text { Kombinacje } \\
\text { Treatments }\end{array}$} & \multirow{2}{*}{$\begin{array}{c}\text { Dawka } \\
\text { Rate } \\
{[1 / \mathrm{kg} / \mathrm{ha}]}\end{array}$} & \multicolumn{4}{|c|}{$\begin{array}{c}\text { Efektywność - Efficacy } \\
{[\%]}\end{array}$} \\
\hline & & 12.08 & 20.08 & 3.09 & 29.09 \\
\hline \multicolumn{6}{|c|}{ Stadia ruchome - Motile forms } \\
\hline Ortus $05 \mathrm{SC}$ & 1,0 & 49,4 & 55,7 & 29,7 & $-37,9$ \\
\hline Ortus $05 \mathrm{SC}$ & 1,25 & 78,4 & 81,2 & 58,7 & 10,2 \\
\hline Ortus 05 SC + Slippa & $1,0+0,2$ & 78,3 & 79,0 & 62,1 & 50,8 \\
\hline Sanmite $20 \mathrm{WP}$ & 2,25 & 82,1 & 90,2 & 92,1 & 82,7 \\
\hline \multicolumn{6}{|c|}{ Jaja - Eggs } \\
\hline Ortus $05 \mathrm{SC}$ & 1,0 & 41,6 & 65,6 & 22,6 & $-47,3$ \\
\hline Ortus $05 \mathrm{SC}$ & 1,25 & 71,2 & 70,2 & 60,7 & 20,6 \\
\hline Ortus 05 SC + Slippa & $1,0+0,2$ & 75,3 & 81,3 & 61,6 & 44,3 \\
\hline Sanmite $20 \mathrm{WP}$ & 2,25 & 82,3 & 88,5 & 88,1 & 81,6 \\
\hline
\end{tabular}

Tabela 5. Efektywność preparatu Ortus $05 \mathrm{SC}$ w zwalczaniu roztocza truskawkowca (P. pallidus) na truskawce wyrażona liczbą stadiów ruchomych oraz jaj na 1 liść. Bobrowa, terminy zabiegów: 9 i 16.07 .2010

Table 5. Efficacy of fenpiroxymate (Ortus 05 SC) in the control of the strawberry mite (P. pallidus) on strawberry expressed as number of motile forms and eggs. Bobrowa, date of treatments: July 9 and 16, 2010

\begin{tabular}{|c|c|c|c|c|c|c|c|}
\hline \multirow{2}{*}{$\begin{array}{l}\text { Kombinacja } \\
\text { Treatment }\end{array}$} & \multirow{2}{*}{$\begin{array}{c}\text { Dawka } \\
\text { Rate } \\
{[1 / \mathrm{kg} / \mathrm{ha}]}\end{array}$} & \multirow{2}{*}{$\begin{array}{l}\text { Przed } \\
\text { zabiegiem } \\
\text { Before } \\
\text { treatment }\end{array}$} & \multicolumn{5}{|c|}{$\begin{array}{l}\text { Liczba osobników na } 1 \text { liść } \\
\text { No. of motile forms and eggs per } 1 \text { leaf }\end{array}$} \\
\hline & & & 16.07 & 23.07 & 30.07 & 6.08 & 13.08 \\
\hline 1 & 2 & 3 & 4 & 5 & 6 & 7 & 8 \\
\hline \multicolumn{8}{|c|}{ Stadia ruchome - Motile forms } \\
\hline Kontrola - Untreated & - & $13,1 \mathrm{a}$ & $47,5 \mathrm{~b}$ & $10,7 \mathrm{~b}$ & $27,7 \mathrm{~b}$ & $41,6 \mathrm{~b}$ & $33,8 \mathrm{~b}$ \\
\hline Ortus $05 \mathrm{SC}$ & 1,125 & $14,4 \mathrm{a}$ & $7,6 \mathrm{a}$ & $5,6 \mathrm{a}$ & $7,9 \mathrm{a}$ & $7,4 \mathrm{a}$ & $4,7 \mathrm{a}$ \\
\hline
\end{tabular}




\begin{tabular}{l|c|c|c|c|c|c|c|c}
\hline \multicolumn{1}{c|}{1} & 2 & 3 & 4 & 5 & 6 & 7 & 8 \\
\hline Ortus 05 SC & 1,5 & $14,0 \mathrm{a}$ & $7,6 \mathrm{a}$ & $3,8 \mathrm{a}$ & $9,1 \mathrm{a}$ & $8,0 \mathrm{a}$ & $7,0 \mathrm{a}$ \\
\hline Ortus 05 SC + Slippa & $1,125+0,2$ & $10,7 \mathrm{a}$ & $4,3 \mathrm{a}$ & $2,8 \mathrm{a}$ & $6,9 \mathrm{a}$ & $4,4 \mathrm{a}$ & $7,4 \mathrm{a}$ \\
\hline Sanmite 20 WP & 2,25 & $15,4 \mathrm{a}$ & $6,1 \mathrm{a}$ & $1,0 \mathrm{a}$ & $0,6 \mathrm{a}$ & $1,0 \mathrm{a}$ & $1,4 \mathrm{a}$ \\
\hline \multicolumn{7}{|c|}{ Jaja - Eggs } \\
\hline Kontrola - Untreated & - & $31,6 \mathrm{a}$ & $83,9 \mathrm{~b}$ & $20,1 \mathrm{~b}$ & $39,7 \mathrm{~b}$ & $67,2 \mathrm{~b}$ & $54,2 \mathrm{~b}$ \\
\hline Ortus 05 SC & 1,125 & $37,3 \mathrm{a}$ & $13,2 \mathrm{a}$ & $10,5 \mathrm{a}$ & $7,0 \mathrm{a}$ & $7,3 \mathrm{a}$ & $9,2 \mathrm{a}$ \\
\hline Ortus 05 SC & 1,5 & $28,7 \mathrm{a}$ & $11,4 \mathrm{a}$ & $7,5 \mathrm{a}$ & $11,2 \mathrm{a}$ & $6,1 \mathrm{a}$ & $10,1 \mathrm{a}$ \\
\hline Ortus 05 SC + Slippa & $1,125+0,2$ & $25,2 \mathrm{a}$ & $8,6 \mathrm{a}$ & $5,1 \mathrm{a}$ & $8,7 \mathrm{a}$ & $3,2 \mathrm{a}$ & $11,4 \mathrm{a}$ \\
\hline Sanmite 20 WP & 2,25 & $29,2 \mathrm{a}$ & $10,2 \mathrm{a}$ & $1,6 \mathrm{a}$ & $0,5 \mathrm{a}$ & $1,2 \mathrm{a}$ & $1,8 \mathrm{a}$ \\
\hline
\end{tabular}

Wartości średnie oznaczone w kolumnach tą samą literą nie różnią się istotnie przy p =0,05, test Newmana-Keulsa

Means followed by the same letter in each column are not significantly different (Newman-Keuls' test, $\mathrm{p}=0.05$ )

Tabela 6. Efektywność zwalczania roztocza truskawkowca (P. pallidus) na truskawce obliczona według wzoru Abbotta [\%]. Bobrowa 2010

Table 6. Efficacy of strawberry mite (P. pallidus) control on strawberry plants according to Abbott's formula [\%]. Bobrowa 2010

\begin{tabular}{|c|c|c|c|c|c|c|}
\hline \multirow{2}{*}{$\begin{array}{l}\text { Kombinacja } \\
\text { Treatment }\end{array}$} & \multirow{2}{*}{$\begin{array}{c}\text { Dawka } \\
\text { Rate } \\
{[1 / \mathrm{kg} / \mathrm{ha}]}\end{array}$} & \multicolumn{5}{|c|}{$\begin{array}{c}\text { Efektywność - Efficacy } \\
{[\%]}\end{array}$} \\
\hline & & 16.07 & 23.07 & 30.07 & 6.08 & 13.08 \\
\hline \multicolumn{7}{|c|}{ Stadia ruchome - Motile forms } \\
\hline Ortus $05 \mathrm{SC}$ & 1,125 & 84,3 & 47,8 & 82,4 & 89,1 & 83,0 \\
\hline Ortus $05 \mathrm{SC}$ & 1,5 & 86,4 & 62,7 & 71,8 & 90,9 & 81,4 \\
\hline Ortus 05 SC + Slippa & $1,125+0,2$ & 89,7 & 74,6 & 78,1 & 95,2 & 89,0 \\
\hline Sanmite $20 \mathrm{WP}$ & 2,25 & 87,8 & 92,0 & 98,7 & 98,2 & 96,7 \\
\hline \multicolumn{7}{|c|}{ Jaja - Eggs } \\
\hline Ortus $05 \mathrm{SC}$ & 1,125 & 84,0 & 47,7 & 71,5 & 82,5 & 86,1 \\
\hline Ortus $05 \mathrm{SC}$ & 1,5 & 84,0 & 64,5 & 67,1 & 82,2 & 79,3 \\
\hline Ortus 05 SC + Slippa & $1,125+0,2$ & 90,9 & 73,8 & 75,1 & 89,4 & 78,1 \\
\hline Sanmite $20 \mathrm{WP}$ & 2,25 & 87,2 & 90,7 & 97,8 & 97,6 & 95,9 \\
\hline
\end{tabular}

Tabela 7. Efektywność preparatu Ortus $05 \mathrm{SC}$ w zwalczaniu roztocza truskawkowca (P. pallidus) na truskawce wyrażona liczbą stadiów ruchomych oraz jaj na 1 liść. Jamno, terminy zabiegów: 28.07 i 6.08 .2010

Table 7. Efficacy of fenpiroxymate (Ortus 05 SC) in the control of the strawberry mite (P. pallidus) on strawberry expressed as number of motile forms and eggs. Jamno, date of treatments: July 28 and August 6, 2010

\begin{tabular}{|c|c|c|c|c|c|c|c|}
\hline \multirow{2}{*}{$\begin{array}{c}\text { Kombinacja } \\
\text { Treatment }\end{array}$} & \multirow{2}{*}{$\begin{array}{c}\text { Dawka } \\
\text { Rate } \\
{[1 / \mathrm{kg} / \mathrm{ha}]}\end{array}$} & \multirow{2}{*}{$\begin{array}{l}\text { Przed } \\
\text { zabiegiem } \\
\text { Before } \\
\text { treatment }\end{array}$} & \multicolumn{5}{|c|}{$\begin{array}{l}\text { Liczba osobników na } 1 \text { liść } \\
\text { No. of motile forms and eggs per } 1 \text { leaf }\end{array}$} \\
\hline & & & 23.07 & 30.07 & 6.08 & 13.08 & 19.08 \\
\hline \multicolumn{8}{|c|}{ Stadia ruchome - Motile forms } \\
\hline Kontrola - Untreated & - & $12,6 \mathrm{a}$ & $11,9 \mathrm{~b}$ & $5,0 \mathrm{~b}$ & $4,1 \mathrm{a}$ & $1,9 \mathrm{a}$ & $6,6 \mathrm{~b}$ \\
\hline Ortus $05 \mathrm{SC}$ & 1,125 & $5,1 \mathrm{a}$ & $1,0 \mathrm{a}$ & $1,7 \mathrm{a}$ & $0,5 \mathrm{a}$ & $0,8 \mathrm{a}$ & $1,2 \mathrm{a}$ \\
\hline Ortus $05 \mathrm{SC}$ & 1,5 & $6,0 \mathrm{a}$ & $1,4 \mathrm{a}$ & $1,4 \mathrm{a}$ & $0,8 \mathrm{a}$ & $0,5 \mathrm{a}$ & $1,1 \mathrm{a}$ \\
\hline Ortus 05 SC + Slippa & $1,125+0,2$ & $2,4 \mathrm{a}$ & $0,7 \mathrm{a}$ & $0,2 \mathrm{a}$ & $1,1 \mathrm{a}$ & $0,3 \mathrm{a}$ & $1,1 \mathrm{a}$ \\
\hline Sanmite $20 \mathrm{WP}$ & 2,25 & $14,3 \mathrm{a}$ & $0,4 \mathrm{a}$ & $0,1 \mathrm{a}$ & $2,5 \mathrm{a}$ & $0,8 \mathrm{a}$ & $0,5 \mathrm{a}$ \\
\hline \multicolumn{8}{|c|}{ Jaja - Eggs } \\
\hline Kontrola-Untreated & - & $14,4 \mathrm{a}$ & $13,8 \mathrm{~b}$ & $8,0 \mathrm{~b}$ & $3,5 \mathrm{a}$ & $2,2 \mathrm{a}$ & $11,7 \mathrm{~b}$ \\
\hline Ortus $05 \mathrm{SC}$ & 1,125 & $7,3 \mathrm{a}$ & $1,9 \mathrm{a}$ & $1,0 \mathrm{a}$ & $0,6 \mathrm{a}$ & $0,9 \mathrm{a}$ & $1,7 \mathrm{a}$ \\
\hline Ortus $05 \mathrm{SC}$ & 1,5 & $6,4 \mathrm{a}$ & $3,5 \mathrm{a}$ & $2,0 \mathrm{a}$ & $0,6 \mathrm{a}$ & $0,8 \mathrm{a}$ & $1,6 \mathrm{a}$ \\
\hline Ortus $05 \mathrm{SC}+$ Slippa & $1,125+0,2$ & $3,5 \mathrm{a}$ & $0,9 \mathrm{a}$ & $0,2 \mathrm{a}$ & $0,8 \mathrm{a}$ & $0,4 \mathrm{a}$ & $1,0 \mathrm{a}$ \\
\hline Sanmite $20 \mathrm{WP}$ & 2,25 & $15,1 \mathrm{a}$ & $0,5 \mathrm{a}$ & $0,1 \mathrm{a}$ & $2,6 \mathrm{a}$ & $1,4 \mathrm{a}$ & $0,7 \mathrm{a}$ \\
\hline
\end{tabular}

Wartości średnie oznaczone $w$ kolumnach tą samą literą nie różnią się istotnie przy $\mathrm{p}=0,05$, test Newmana-Keulsa

Means followed by the same letter in each column are not significantly different (Newman-Keuls' test, $p=0.05$ ) 
Tabela 8. Efektywność zwalczania roztocza truskawkowca (P. pallidus) na truskawce obliczona według wzoru Abbotta [\%]. Jamno 2010

Table 8. Efficacy of strawberry mite (P. pallidus) control on strawberry plants according to Abbott's formula [\%]. Jamno 2010

\begin{tabular}{|c|c|c|c|c|c|c|}
\hline \multirow{2}{*}{$\begin{array}{l}\text { Kombinacja } \\
\text { Treatment }\end{array}$} & \multirow{2}{*}{$\begin{array}{c}\text { Dawka } \\
\text { Rate } \\
{[1 / \mathrm{kg} / \mathrm{ha}]}\end{array}$} & \multicolumn{5}{|c|}{$\begin{array}{c}\text { Efektywność - Efficacy } \\
{[\%]}\end{array}$} \\
\hline & & 23.07 & 30.07 & 6.08 & 13.08 & 19.08 \\
\hline \multicolumn{7}{|c|}{ Stadia ruchome - Motile forms } \\
\hline Ortus $05 \mathrm{SC}$ & 1,125 & 91,6 & 66,0 & 87,8 & 57,9 & 81,8 \\
\hline Ortus $05 \mathrm{SC}$ & 1,5 & 88,2 & 72,0 & 80,5 & 73,7 & 83,3 \\
\hline Ortus 05 SC + Slippa & $1,125+0,2$ & 94,1 & 96,0 & 73,2 & 84,2 & 83,3 \\
\hline Sanmite $20 \mathrm{WP}$ & 2,25 & 96,6 & 98,4 & 39,0 & 57,9 & 83,3 \\
\hline \multicolumn{7}{|c|}{ Jaja - Eggs } \\
\hline Ortus $05 \mathrm{SC}$ & 1,125 & 86,2 & 87,5 & 82,9 & 59,1 & 85,5 \\
\hline Ortus $05 \mathrm{SC}$ & 1,5 & 74,6 & 75,0 & 82,9 & 63,6 & 86,3 \\
\hline Ortus 05 SC + Slippa & $1,125+0,2$ & 93,5 & 97,5 & 77,1 & 81,8 & 91,5 \\
\hline Sanmite $20 \mathrm{WP}$ & 2,25 & 96,4 & 99,0 & 25,7 & 36,4 & 94,0 \\
\hline
\end{tabular}

substancja czynna preparatu Envidor 204 SC (Labanowska 2006d), spirotetramatu - Movento 100 SC, ale dotychczas żaden z nich nie uzyskał rejestracji do ochrony truskawki.

Efektywność preparatu Ortus 05 SC była zbliżona do uzyskanej po zastosowaniu preparatu porównawczego Sanmite 20 WP. Warto nadmienić, że Ortus 05 SC w dawce 1,0 1/ha wykazał niższą skuteczność w porównaniu z dawkami wyższymi - 1,25 i 1,5 l/ha. Na roślinach kontrolnych zwykle notowano bardzo wysoką liczebność szkodnika. Przedstawione wyniki własne były podstawą do zarejestrowania preparatu Ortus 05 SC do zwalczania roztocza truskawkowca na truskawce, niestety może on być zastosowany tylko jeden raz w sezonie wegetacji (rejestracja na uprawy małoobszarowe). Wydaje się, że przyjęto takie rozwiązanie, by ograniczyć i opóźnić selekcję ras szkodnika odpornych na tę grupę akarycydów (pirydaben - substancja czynna preparatu Sanmite 20 WP należy do tej samej grupy chemicznej - inhibitorów mitochondrialnego transportu elektronów - METI).

\section{Wnioski / Conclusions}

1. Preparat Ortus $05 \mathrm{SC}$ w dawkach 1,125 i 1,5 $1 /$ ha oraz Ortus $05 \mathrm{SC}$ w dawce 1,125 1/ha + Slippa 0,2 1/ha zastosowany dwukrotnie na plantacji zasiedlonej przez bardzo liczną populację roztocza truskawkowca zwalczał lub wykazał średni poziom zwalczania szkodnika.

2. Efektywność akarycydu Ortus $05 \mathrm{SC}(1,25$ 1/ha) i Ortus 05 SC (1,0 1/ha) + Slippa (0,2 1/ha) zastosowanego dwukrotnie po zbiorze truskawki przez 2-3 tygodnie była podobna.

3. Skuteczność preparatu Ortus $05 \mathrm{SC}$ zasadniczo nie różniła się od efektywności preparatu standardowego Sanmite $20 \mathrm{WP}$, choć liczebność roztocza na roślinach chronionych badanym środkiem była nieco wyższa.

\section{Podziękowanie / Acknowledgements}

Składam serdeczne podziękowanie Pani Małgorzacie Gruchała za pomoc w prowadzeniu doświadczeń.

\section{Literatura / References}

Alford D.V. 1972. The effect of Tarsonemus fragariae Zimmermann (Acarina: Tarsonemidae) on strawberry yields. Ann. App. Biol. 70: $13-18$.

Alford D.V. 2007. Pests of Fruit Crops a Color Handbook. Manson Publishing Ltd.: 419-420.

Cross J.V., Burgess C.M., Hanks G.R. 1996. Integrating insecticide use with bilogical control of two-spotted spider mite (Tetranychus urticae) by Phytoseiulus persimilis on strawberry in the UK. Vol. 3. p. 899-906. The BCPC Conference - Pests and Diseases. United Kingdom, Brighton, November 18-21, 1996, 1242 pp.

Easterbrook M.A., Fitzgerald J.D., Solomon M.G. 2001. Biological control of strawberry tarsonemidmite Phytonemus pallidus and twospotted spider mite Tetranychus urticae on strawberry in UK using species of Neoseiulus (Amblyseius) (Acari: Phytoseiidae). Exp. Appl. Acarol. 25 (1): 25-36.

Edland T. 1994. Side-effects on fungicide and insecticide spray on phytoseiid mites in apple orchards. Norveg. J. Agric. Sci. 17: 195-204.

Labanowska B.H. 1992. Effectiveness of the acaricides in the control of the strawberry mite - Phytonemus pallidus ssp. fragariae Zimm. Fruit Sci. Rep. 19 (3): 137-146.

Łabanowska B.H. 1995. Acaricides for control of the strawberry mite - Phytonemus pallidus ssp. fragariae Zimm. p. 633-637. Proc. Symp. "The Acari" II Symposium EURACC (European Association of Acarologist) (D. Kropczyńska, J. Boczek, A. Tomczyk, eds). Krynica, 31.08-5.09.1992. Oficyna Dabor, Warszawa, 698 pp. 
Łabanowska B.H. 2000. Harmfulness of the strawberry mite (Phytonemus pallidus ssp. fragariae Zimm.) and the two-spotted spider mite (Tetranychus urticae Koch.) on the strawberry and susceptibility of some cultivars for infestation. p. 358-361. Materiały 26 Symposjum Akarologicznego „Akarologia Polska u progu nowego tysiąclecia”. Kazimierz Dolny, 24-26. 10. 1999. SGGW, Warszawa, 389 pp.

Łabanowska B.H. 2003. Zwalczanie roztocza truskawkowca (Phytonemus pallidus ssp. fragariae), nowymi akarycydami. [Control of strawberry mite (Phytonemus pallidus ssp. fragariae Zimm.) with new acaricides, in polish with English summary]. Prog. Plant Prot./Post. Ochr. Roślin 43 (2): 781-783.

Łabanowska B.H. 2004. Spread of the strawberry mite (Phytonemus palidus ssp. fragariae Zimm.) on thirteen strawberry cultivars. J. Fruit Ornam. Plant Res. 12: 105-111.

Labanowska B.H. 2006a. Pottential agents for controlling the strawberry mite (Phytonemus palidus ssp. fragariae Zimm.) after the withrawal of endosulfan. J. Fruit Ornam. Plant Res. 14 (Suppl. 3): 67-72.

Łabanowska B.H. 2006b. Susceptibillity of strawberry cultivars to infestation by the strawberry mite (Phytonemus palidus ssp. fragariae Zimm.). J. Fruit Ornam. Plant Res. 14: 189-197.

Łabanowska B.H. 2006c. Efficiency of new-generation acaricides in controlling the strawberry mite - Phytonemus palidus ssp. fragariae Zimm. on strawberry. Biol. Lett. 43 (2): 335-340.

Łabanowska B.H. 2006d. Envidor 240 SC - a new acaricides and its efficacy in controlling strawberry mite (Phytonemus palidus ssp. fragariae Zimm.) and two-spotted spider mite (Tetranychus urticae Koch) on strawberry in Poland. IOBC/WPRS Bull. 29 (9): $115-122$.

Łabanowska B.H. 2007. Efektywność wybranych akarycydów nowej generacji w zwalczaniu przędziorka chmielowca (Tetranychus urticae Koch) na truskawce. [Efficacy of some new generation acaricides in the control of two-spotted spider mite (Tetranychus urticae Koch) on strawberry]. Zesz. Nauk. ISiK 15: 87-92.

Łabanowska B.H. 2011. The big bud mite Cecidophyopsis ribis (Westw.) as a pest of blackcurrant and the possibility of its control in Poland. IOBC/WPRS Bull. 70: 87-92.

Raudonis L. 2002. Monitoring of harmful insects and mites of strawberries. Hort. Veg. Grow. 21 (4): 102-110.

Raudonis L. 2005. Effect of spirodiclofen on the strawberry mite, Tarsonemus pallidus (Acari: Tarsonemidae) in strawberries. Sodinninkyste ir Darzininkyste. Babtai 24 (2): 64-67.

Raudonis L. 2006a. Comparative toxicity of spirodiclofen and lambdacihalotrin to Tetranychus urticae, Tarsonemus pallidus and predatory mite Amblyseius andersoni in a strawberry site under field conditions. Agron. Res. 4: 317-322.

Raudonis L. 2006b. The effect of abamectin on strawberry mite Tarsonemus pallidus (Acari: Tarsonemidae) in strawberries. Scientific Works of the Lithuanian Institute of Horticulture and Lithuanian University of Agriculture, Sodininkyste ir Darzininkyste 25 (4): $153-161$.

Stenseth C., Nordby A. 1976. Damage and control of strawberry mite Steneotarsonemus pallidus (Acarina - Tarsenemidae), on strawberries. J. Hort. Sci. 51 (1): 49-54.

Svensson B. 2008. Successful bio-control of the strawberry mite Phytonemus pallidus with the predatory mite Neoseiulus cucumeris in organic outdoor production of strawberries (Fragaria $\times$ ananassa Duch.) in Sweden. ISHS Acta Hort. 842 (2): 657-660.

Tuovinen T. 2000. Integrated control of strawberry mite (Phytonemus pallidus) in the Nordic multi-year growing system. ISHS Acta Hort. 525: 389-392. 